\title{
Intraperitoneal, but not retroperitoneal, visceral adipose tissue is associated with diabetes mellitus: a cross-sectional, retrospective pilot analysis
}

\author{
Muhei Tanaka ${ }^{1 *} \mathbb{0}$, Hiroshi Okada ${ }^{2}$, Yoshitaka Hashimoto ${ }^{1}$, Muneaki Kumagai ${ }^{3}$, Hiromi Nishimura ${ }^{3}$ \\ and Michiaki Fukui ${ }^{1}$
}

\begin{abstract}
Aim: Diabetes mellitus (DM) is associated with adverse outcomes, and visceral adipose tissue (VAT), classified into intraperitoneal VAT (IVAT) and retroperitoneal VAT (RVAT), is associated with insulin resistance. This study aimed to evaluate the association of IVAT and RVAT with the prevalence or incidence of DM.

Methods: In this cross-sectional, retrospective, cohort study, the prevalence and incidence of DM was analyzed in 803 and 624 middle-aged Japanese participants, respectively. The cross-sectional area of the abdominal adipose tissue was evaluated from an unenhanced computed tomography scan at the third lumbar vertebrae, and the IVAT or RVAT was analyzed using specialized software. The areas were normalized for the square value of the participants' height in meters and described as the IVAT or RVAT area index.

Results: The IVAT area index (adjusted odds ratio [OR], 1.04; 95\% confidence intervals [CI], 1.02-1.07, per $1.0 \mathrm{~cm}^{2} / \mathrm{m}^{2}$ ) or IVAT/RVAT area ratio $(1.89 ; 1.23-2.85$, per 1.0$)$ was independently associated with the prevalence of DM, whereas the RVAT area index was not. During a follow-up (mean) of 3.7 years, 30 participants were diagnosed with DM. The IVAT area index (adjusted hazards ratio [HR], 1.02; $95 \% \mathrm{Cl} 1.003-1.04$, per $\left.1.0 \mathrm{~cm}^{2} / \mathrm{m}^{2}\right)$ or IVAT/RVAT area ratio $(2.25$; 1.40-3.43, per 1.0) was independently associated with the incidence of DM, whereas the RVAT area index was not.
\end{abstract}

Conclusions: IVAT, but not RVAT, is associated with the prevalence or incidence of DM.

Keywords: Intraperitoneal visceral adipose tissue, Retroperitoneal visceral adipose tissue, Diabetes mellitus, Subcutaneous adipose tissue, Insulin resistance

\section{Background}

It is already well established in the literature that diabetes mellitus (DM) have a higher risk of atherosclerosis and cardiovascular disease $[1,2]$. There exists a close relationship between visceral adipose tissue (VAT) and, both,

\footnotetext{
*Correspondence: muhei-t@koto.kpu-m.ac.jp

${ }^{1}$ Department of Endocrinology and Metabolism, Kyoto Prefectural

University of Medicine, Graduate School of Medical Science, 465 Kajii-cho, Kawaramachi-Hirokoji, Kamigyo-ku, Kyoto 602-8566, Japan

Full list of author information is available at the end of the article
}

peripheral and hepatic insulin resistance in patients with type 2 DM [3].

Obesity includes many different anatomical, physiological and pathological phenotypes, and both total adiposity and regional fat distribution influence metabolism [4-6]. Abdominal adipose tissue can be differentiated into subcutaneous adipose tissue (SAT) and VAT, which have different functions in lipid and glucose metabolism [7]. The VAT volumes are associated with the metabolic consequences of obesity $[8,9]$, although investigations concerning SAT have revealed controversial results [8].

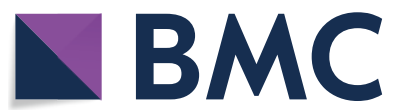

(c) The Author(s) 2020. This article is licensed under a Creative Commons Attribution 4.0 International License, which permits use, sharing, adaptation, distribution and reproduction in any medium or format, as long as you give appropriate credit to the original author(s) and the source, provide a link to the Creative Commons licence, and indicate if changes were made. The images or other third party material in this article are included in the article's Creative Commons licence, unless indicated otherwise in a credit line to the material. If material is not included in the article's Creative Commons licence and your intended use is not permitted by statutory regulation or exceeds the permitted use, you will need to obtain permission directly from the copyright holder. To view a copy of this licence, visit http://creativecommons.org/licenses/by/4.0/. The Creative Commons Public Domain Dedication waiver (http://creativecommons.org/publicdomain/zero/1.0/) applies to the data made available in this article, unless otherwise stated in a credit line to the data. 
Moreover, SAT and VAT can be further distinguished as deep and superficial SAT and intraperitoneal and retroperitoneal VAT, respectively [9-12]; whereas the deep and superficial SAT have different functions [13-15], the difference between the intraperitoneal and retroperitoneal VAT has not been examined.

Computed tomography (CT) scanning is the gold standard investigational method to analyze the SAT and VAT $[16,17]$. Recently, a study showed that the site-specific measurement of abdominal adipose tissue (intraperitoneal and retroperitoneal VAT, or deep and superficial SAT) evaluated by CT scanning demonstrated high repeatability [9].

Therefore, in this study, we investigated whether the intraperitoneal and retroperitoneal VAT areas, as evaluated by $\mathrm{CT}$, were associated with the prevalence or incidence of DM in middle-aged Japanese participants.

\section{Materials and methods}

\section{Participants and study design}

The Nishimura Health Survey is an ongoing cohort investigation of risk factors for chronic diseases including metabolic syndrome, hypertension, chronic kidney disease, non-alcoholic fatty liver disease, and diabetes mellitus [18-21]. The Nishimura Clinic (Kyoto, Japan) provides regular health check-up for employees of various companies. A cross-sectional study as well as a retrospective cohort study with mean and median follow-up durations of 3.7 and 4.0 years were performed to evaluate the site-specific measurement of abdominal fat and its correlation with the prevalence or incidence of DM. From the 20,852 individuals who underwent physical health checkups from April 2013 to March 2018, 830 individuals who had undergone abdominal CT scanning were evaluated for study inclusion. In Japan, yearly routine examination for employees is legally mandated, and all or most of the costs for the health check-up are usually paid by their employers. Although abdominal CT scanning was not part of the basic examinations, it was performed on request of 830 individuals. Individuals were excluded in case of incomplete data, difficulty with segmenting the adipotic areas (because the fascia separating the areas could not be visualized), renal dysfunction, and high C-reactive protein (CRP) levels (Fig. 1), because active infection, systemic inflammatory processes, and kidney dysfunction can also affect glucose metabolism. Additionally, participants were excluded from this cohort study if they had no data on follow-up examinations and if they were diagnosed with DM at the baseline examination. Finally, in this cross-sectional, retrospective, cohort study, the prevalence and incidence of DM was analyzed in 803 and 624 participants, and 30 participants were newly diagnosed with DM during the study period. All

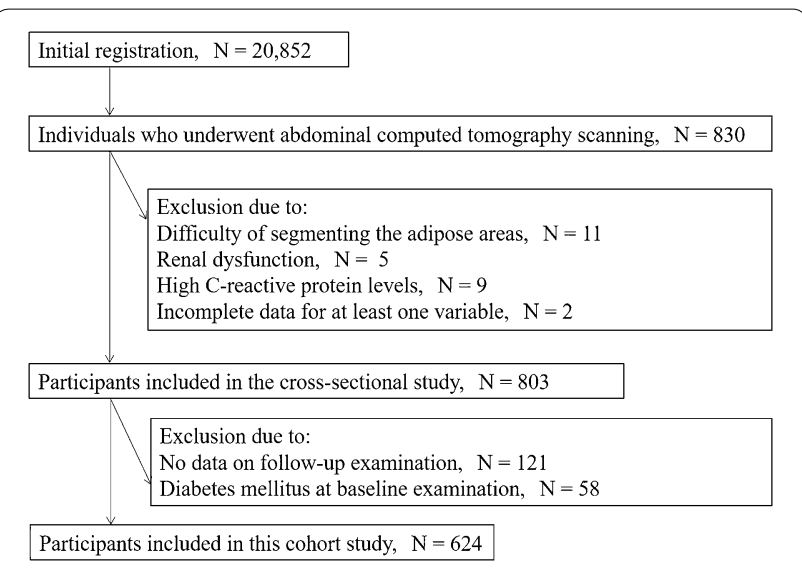

Fig. 1 Flowchart of the screening and inclusion and exclusion of study participants

procedures were approved by the Local Research Ethics Committee of the Kyoto Prefectural University of Medicine (ERB-C-1017-1) and conducted in accordance with the Declaration of Helsinki. All study participants provided informed consent for study participation.

\section{Data collection and measurements, and definitions}

Demographic data and biomarkers were assessed as described previously [18-21], and the biomarkers evaluated included fasting plasma glucose (FPG), triglycerides, low-density lipoprotein cholesterol (LDL-C), high-density lipoprotein cholesterol (HDL-C), creatinine, and CRP levels. Smoking was defined as current tobacco use. Alcohol drinking habits were evaluated based on the amount and frequency of alcoholic beverage intake during the past month, which was converted to daily alcohol intake. Subjects were classified as positive for alcohol drinking if the consumption exceeded $30 \mathrm{~g} /$ day and $20 \mathrm{~g} /$ day for men and women respectively. When subjects had performed any kind of physical activity for at least $30 \mathrm{~min} /$ day regularly, they were categorized as regular exercisers. According to the American Diabetes Association, diabetes mellitus was defined as having a HbA1c level $\geq 6.5 \% \quad(48 \mathrm{mmol} / \mathrm{mol}), \quad$ FPG $\quad$ level $\geq 126 \mathrm{mg} / \mathrm{dL}$ $(7.0 \mathrm{mmol} / \mathrm{L})$, in addition to a medical history of diabetes, or current use of antidiabetic agents [22]. Hypertension was defined as a systolic blood pressure $>140 \mathrm{mmHg}$, or a diastolic blood pressure $>90 \mathrm{mmHg}$, in addition to a medical history of hypertension, or current use of antihypertensive agents. Dyslipidemia was defined as either or a combination of LDL-C $\geq 4.14 \mathrm{mmol} / \mathrm{L}$ $(160 \mathrm{mg} / \mathrm{dL}), H D L-C<1.03 \mathrm{mmol} / \mathrm{L}(40 \mathrm{mg} / \mathrm{dL})$, or triglyceride level $\geq 1.69 \mathrm{mmol} / \mathrm{L}(150 \mathrm{mg} / \mathrm{dl})$, in addition to a medical history of dyslipidemia, or current use of lipid-lowering agents. High CRP level was defined 
as values $>95.2 \mathrm{nmol} / \mathrm{L}(10 \mathrm{mg} / \mathrm{L})$. Renal dysfunction was defined based on a serum creatinine threshold $>106.1 \mu \mathrm{mol} / \mathrm{L}(1.2 \mathrm{mg} / \mathrm{dL})$.

\section{Assessment of abdominal adipose tissue area}

The CT settings and analysis software have been described in previous studies [18-21]. The cross-sectional area of the abdominal adipose tissue was evaluated from an unenhanced CT scan at the third lumbar vertebrae, and was semi-automatically calculated by a welltrained technician who was blinded to the participant's identity and clinical presentation. The VAT (including IVAT, and RVAT) and SAT (including DSAT, and SSAT) were identified and quantified using Hounsfield unit (HU) thresholds of -150 to -50 and -190 to $-30 \mathrm{HU}$, respectively [23]. The intraperitoneal and retroperitoneal VAT (IVAT, and RVAT), and deep and superficial SAT (DSAT, and SSAT) were identified and quantified according to a method that was reported in the literature [9]. The cross-sectional areas were normalized for the square of the participants' height in meters and described as the VAT, SAT, IVAT, RVAT, DSAT, or SSAT area indices. Additionally, we calculated VAT/SAT, IVAT/RVAT, and DSAT/SSAT ratios as the area ratios of VAT area index divided by SAT area index, the area ratio of IVAT area index divided by RVAT area index, and the area ratio of DSAT area index divided by SSAT area index, respectively. The intraclass correlation coefficients for each VAT, SAT, IVAT, RVAT, DSAT, or SSAT area indices from 200 random subset samples were all $>0.94$.

\section{Study endpoints}

This study has been designed to investigate potential different associations between DM and IVAT and RVAT. We particularly focused on middle-aged Japanese participants. The primary end-point was to determine whether IVAT and RVAT have different associations with the prevalence of DM. The secondary endpoint was to determine whether IVAT is able to predict incidence of DM.

\section{Statistical analysis}

No formal sample size calculation was performed, because previous studies were not available regarding the relationship between DM and IVAT or RVAT. Continuous parameters are presented as mean \pm standard deviation, and categorical parameters are presented as number (percentage). A skewed variable, such as CRP, was presented as median (interquartile range). The Student's $t$-test or chi-square test was performed to assess the significance of differences between the two groups. The Pearson correlation coefficient was used to measure the strength of a linear association between two continuous parameters. Originally showing a skewed distribution,
CRP level was log transformed. Logistic regression analysis was used to assess the association of the parameters of abdominal adipose tissue area with the prevalence of DM. We have evaluated the coefficient of determination between all independent variables to detect multicollinearity, and all values did not exceeds 0.7 . The adjusted odds ratios (ORs) of each parameter of the abdominal adipose tissue area for the prevalence of DM were calculated; to avoid excessive overfitting, the following parameters were used simultaneously as independent variables: Model 1: age, sex, body mass index, and each parameter for abdominal adipose tissue area; Model 2: Model 1 plus prevalence of hypertension, and dyslipidemia; and Model 3: Model 1 plus C-reactive protein, and creatinine levels. Additionally, to analyze the IVAT, RVAT, DSAT, and SSAT area indices simultaneously, the adjusted ORs for the prevalence of DM were calculated; to avoid excessive overfitting, the following parameters were used simultaneously as independent variables: age, sex, body mass index, and the IVAT, RVAT, DSAT and SSAT area indices. Multiple regression analysis was performed to explore the associations between the CRP levels and the parameters of abdominal adipose tissue area in the cross-sectional study. Multiple Cox regression analyses were performed to calculate the hazards ratio (HR) of each parameter of the abdominal adipose tissue area for incident DM. To avoid excessive overfitting, the following parameters were simultaneously used as independent variables: Model 1: age, sex, fasting plasma glucose at baseline examination, and each parameter for abdominal adipose tissue area, Model 2: Model 1 plus body mass index. To compare which abdominal fat compartment is more informative compared other compartment and to its ratios, we have conducted both receiver operator characteristic (ROC) curves and Bayesian Information Criterions analyses. The ROC analyses were performed to calculate the area under the ROC curves (AUC) of the IVAT, RVAT, DSAT, and SSAT area indices, and VAT/ SAT, IVAT/RVAT and DSAT/SSAT area ratios for the prevalence of DM. We also compared the AUC between the two groups. A $P$-value of $<0.05$ was considered significant. Statistical analyses were performed using the JMP version 11.0 software (SAS Institute Inc., Cary, NC, USA).

\section{Results}

In the cross-sectional study, there were significant differences between the participants with and without DM in regard to the total adipose tissue area index; VAT, SAT, IVAT, RVAT, DSAT, and SSAT area indices; and VAT/ SAT, IVAT/RVAT and DSAT/SSAT area ratios (Table 1). The participants with DM were older, and had a higher body mass index. Therefore, we have evaluated the 
Table 1 Clinical characteristics of study participants in this cross-sectional and retrospective cohort studies

\begin{tabular}{|c|c|c|c|c|c|c|}
\hline & \multicolumn{3}{|c|}{ Cross-sectional study } & \multicolumn{3}{|c|}{ Retrospective cohort study } \\
\hline & $\begin{array}{l}\text { Prevalence of DM } \\
(-)\end{array}$ & Prevalence of DM (+) & $P$ & Incidence of DM (-) & Incidence of DM (+) & $P$ \\
\hline$n$ & 745 & 58 & & 594 & 30 & \\
\hline Age (years) & $50.6 \pm 10.6$ & $58.6 \pm 9.5$ & $<0.0001$ & $50.8 \pm 10.6$ & $54.4 \pm 9.8$ & 0.0703 \\
\hline Male & $458(61.5)$ & $48(82.8)$ & 0.0012 & $370(62.3)$ & $24(80.0)$ & 0.0498 \\
\hline Body mass index $\left(\mathrm{kg} / \mathrm{m}^{2}\right)$ & $22.6 \pm 3.4$ & $25.8 \pm 4.9$ & $<0.0001$ & $22.6 \pm 3.4$ & $25.7 \pm 4.5$ & $<0.0001$ \\
\hline $\begin{array}{l}\text { Family history of diabetes } \\
\text { mellitus }\end{array}$ & $102(13.7)$ & $22(37.9)$ & $<0.0001$ & $516(86.9)$ & $25(83.3)$ & 0.5780 \\
\hline Current smoker & $120(16.1)$ & $18(31.0)$ & 0.0037 & $500(84.2)$ & $24(80.0)$ & 0.5431 \\
\hline Regular exercise & $195(26.2)$ & $25(43.1)$ & 0.0054 & $434(73.1)$ & $25(83.3)$ & 0.2134 \\
\hline Alcohol drinking habit & $163(21.9)$ & $13(22.4)$ & 0.9245 & $464(78.1)$ & $22(73.3)$ & 0.5381 \\
\hline Hypertension & $192(25.8)$ & $31(53.5)$ & $<0.0001$ & $441(74.2)$ & $19(63.3)$ & 0.1854 \\
\hline Dyslipidemia & $220(29.5)$ & $35(60.3)$ & $<0.0001$ & $420(70.7)$ & $19(63.3)$ & 0.3882 \\
\hline C-reactive protein ${ }^{\mathrm{a}}(\mathrm{nmol} / \mathrm{L})$ & $1.9(1.9-7.6)$ & $7.6(4.3-24.8)$ & $<0.0001$ & $1.9(1.9-6.9)$ & $8.6(1.9-11.7)$ & 0.0020 \\
\hline Creatinine $(\mu \mathrm{mol} / \mathrm{L})$ & $68.3 \pm 13.5$ & $72.6 \pm 13.9$ & 0.0208 & $68.5 \pm 13.6$ & $74.4 \pm 11.0$ & 0.0195 \\
\hline $\begin{array}{l}\text { Fasting plasma glucose } \\
(\mathrm{mmol} / \mathrm{L})\end{array}$ & $5.3 \pm 0.5$ & $8.0 \pm 2.1$ & $<0.0001$ & $5.3 \pm 0.4$ & $6.1 \pm 0.5$ & $<0.0001$ \\
\hline $\begin{array}{l}\text { Total adipose tissue area index } \\
\left(\mathrm{cm}^{2} / \mathrm{m}^{2}\right)\end{array}$ & $79.4 \pm 40.2$ & $123.3 \pm 59.0$ & $<0.0001$ & $77.8 \pm 39.9$ & $111.1 \pm 37.0$ & $<0.0001$ \\
\hline VAT area index $\left(\mathrm{cm}^{2} / \mathrm{m}^{2}\right)$ & $31.5 \pm 21.2$ & $58.6 \pm 24.9$ & $<0.0001$ & $30.7 \pm 21.0$ & $51.2 \pm 19.5$ & $<0.0001$ \\
\hline IVAT area index $\left(\mathrm{cm}^{2} / \mathrm{m}^{2}\right)$ & $19.3 \pm 14.6$ & $38.3 \pm 17.7$ & $<0.0001$ & $18.8 \pm 14.4$ & $33.1 \pm 14.2$ & $<0.0001$ \\
\hline RVAT area index $\left(\mathrm{cm}^{2} / \mathrm{m}^{2}\right)$ & $12.2 \pm 7.5$ & $20.0 \pm 9.4$ & $<0.0001$ & $12.0 \pm 7.4$ & $18.1 \pm 7.1$ & $<0.0001$ \\
\hline SAT area index $\left(\mathrm{cm}^{2} / \mathrm{m}^{2}\right)$ & $47.9 \pm 24.7$ & $64.6 \pm 43.8$ & $<0.0001$ & $47.1 \pm 24.3$ & $59.9 \pm 27.0$ & 0.0053 \\
\hline DSAT area index $\left(\mathrm{cm}^{2} / \mathrm{m}^{2}\right)$ & $27.9 \pm 15.1$ & $40.6 \pm 26.3$ & $<0.0001$ & $27.5 \pm 15.1$ & $36.7 \pm 15.3$ & 0.0012 \\
\hline SSAT area index $\left(\mathrm{cm}^{2} / \mathrm{m}^{2}\right)$ & $20.0 \pm 11.4$ & $24.4 \pm 20.4$ & 0.0090 & $19.6 \pm 11.2$ & $23.2 \pm 14.3$ & 0.0910 \\
\hline VAT/SAT area ratio & $0.7 \pm 0.4$ & $1.1 \pm 0.5$ & $<0.0001$ & $0.7 \pm 0.4$ & $1.0 \pm 0.4$ & 0.0001 \\
\hline IVAT/RVAT area ratio & $1.6 \pm 0.7$ & $2.0 \pm 0.6$ & $<0.0001$ & $1.5 \pm 0.7$ & $1.9 \pm 0.7$ & 0.0017 \\
\hline DSAT/SSAT area ratio & $1.5 \pm 0.6$ & $1.8 \pm 0.6$ & 0.0001 & $1.5 \pm 0.6$ & $1.8 \pm 0.7$ & 0.0107 \\
\hline
\end{tabular}

Continuous variables are presented as mean \pm 1 standard deviation, or median (interquartile range), and categorical variables are presented as number (percentage) DM diabetes mellitus, VAT visceral adipose tissue, IVAT intraperitoneal VAT, RVAT retroperitoneal VAT, SAT subcutaneous adipose tissue, DSAT deep SAT, SSAT superficial SAT. ${ }^{a}$ Values were analyzed after log transformation

association between these variables and adipose tissue parameters. Age was positively associated with the total adipose tissue area index; VAT, IVAT, RVAT, and DSAT area indices; and VAT/SAT, IVAT/RVAT and DSAT/ SSAT area ratios. Body mass index was positively associated with the total adipose tissue area index; VAT, SAT, IVAT, RVAT, DSAT, and SSAT area indices; and VAT/ SAT, IVAT/RVAT and DSAT/SSAT area ratios. Male participants had higher VAT, IVAT, and RVAT area indices; and VAT/SAT, IVAT/RVAT and DSAT/SSAT area ratios, and had lower SAT, DSAT, and SSAT area indices.

In the adjusted model 3, the VAT area index (OR, 1.03; $95 \%$ confidence interval (CI), $1.01-1.05$, per $1.0 \mathrm{~cm}^{2} /$ $\mathrm{m}^{2}$ ) or the IVAT area index (OR, 1.04; 95\% CI 1.02-1.07, per $1.0 \mathrm{~cm}^{2} / \mathrm{m}^{2}$ ) was independently associated with the prevalence of DM, whereas the RVAT area index was not (Table 2). Moreover, in the same model, the VAT/SAT area ratio (OR, 3.21; 95\% CI 1.49-6.83, per 1.0) or the IVAT/ RVAT area ratio (OR, 1.89; 95\% CI 1.23-2.85, per 1.0) was independently associated with the prevalence of DM. In the adjusted model 1 and 2, similar results were obtained. After adjusting for age, sex, body mass index and family history of diabetes mellitus, the IVAT (OR, 1.05; 95\% CI $1.02-1.08$, per $1.0 \mathrm{~cm}^{2} / \mathrm{m}^{2}$ ) or RVAT (OR, 1.05; $95 \%$ CI $1.002-1.10$, per $1.0 \mathrm{~cm}^{2} / \mathrm{m}^{2}$ ) area index was independently associated with the prevalence of DM. Besides, after adjusting for age, sex, body mass index, smoking status, and exercise habits, the IVAT (OR, 1.05; 95\% CI 1.02-1.07, per $1.0 \mathrm{~cm}^{2} / \mathrm{m}^{2}$ ) or RVAT (OR, 1.05 ; $95 \%$ CI $1.002-1.10$, per $1.0 \mathrm{~cm}^{2} / \mathrm{m}^{2}$ ) area index was independently associated with the prevalence of DM. However, in the adjusted model 1.2 and 3, the RVAT area index was not independently associated with the prevalence of DM.

When the IVAT, RVAT, DSAT, and SSAT area indices were used simultaneously as independent variables, the IVAT area index was independently associated with the prevalence of DM, whereas the RVAT, DSAT, and SSAT area indices were not (Table 3 ). 
Table 2 Adjusted odds ratio and $95 \%$ confidence interval of each abdominal adipose tissue area parameter for the prevalence of diabetes mellitus

\begin{tabular}{llll}
\hline & Model 1 & Model 2 & Model 3 \\
\hline Total adipose tissue area index, per $1.0 \mathrm{~cm}^{2} / \mathrm{m}^{2}$ & $1.02(1.01-1.04)^{*}$ & $1.02(1.01-1.04)^{*}$ & $1.02(1.01-1.04)^{*}$ \\
VAT area index, per $1.0 \mathrm{~cm}^{2} / \mathrm{m}^{2}$ & $1.03(1.01-1.05)^{*}$ & $1.03(1.01-1.05)^{*}$ & $1.03(1.01-1.05)^{*}$ \\
IVAT area index, per $1.0 \mathrm{~cm}^{2} / \mathrm{m}^{2}$ & $1.04(1.02-1.07)^{*}$ & $1.04(1.01-1.06)^{*}$ & $1.04(1.02-1.07)^{*}$ \\
RVAT area index, per $1.0 \mathrm{~cm}^{2} / \mathrm{m}^{2}$ & $1.04(0.99-1.09)$ & $1.03(0.98-1.08)$ & $1.03(0.99-1.08)$ \\
SAT area index, per $1.0 \mathrm{~cm}^{2} / \mathrm{m}^{2}$ & $1.01(0.99-1.03)$ & $1.01(0.99-1.04)$ & $1.01(0.99-1.03)$ \\
DSAT area index, per $1.0 \mathrm{~cm}^{2} / \mathrm{m}^{2}$ & $1.02(0.99-1.05)$ & $1.02(0.99-1.05)$ & $1.01(0.99-1.04)$ \\
SSAT area index, per $1.0 \mathrm{~cm}^{2} / \mathrm{m}^{2}$ & $1.02(0.98-1.05)$ & $1.02(0.98-1.05)$ & $1.02(0.98-1.05)$ \\
VAT/SAT area ratio, per 1.0 & $3.30(1.55-6.95)^{*}$ & $2.95(1.35-6.37)^{*}$ & $3.21(1.49-6.83)^{*}$ \\
IVAT/RVAT area ratio, per 1.0 & $1.94(1.27-2.91)^{*}$ & $1.86(1.20-2.83)^{*}$ & $1.89(1.23-2.85)^{*}$ \\
DSAT/SSAT area ratio, per 1.0 & $1.07(0.67-1.59)$ & $1.09(0.67-1.65)$ & $1.01(0.62-1.52)$ \\
\hline
\end{tabular}

The following parameters were simultaneously used as independent variables: Model 1: age, sex, body mass index, and each parameter for abdominal adipose tissue area, Model 2: Model 1 plus prevalence of hypertension, and dyslipidemia, Model 3: Model 1 plus C-reactive protein, and creatinine levels

VAT visceral adipose tissue, IVAT intraperitoneal VAT, RVAT retroperitoneal VAT, SAT subcutaneous adipose tissue, DSAT deep SAT, SSAT superficial SAT

${ }^{*} P<0.05$

Table 3 Adjusted odds ratios and $95 \%$ confidence intervals for the prevalence of diabetes mellitus

Odds ratios and $95 \%$ confidence intervals

IVAT area index, per $1.0 \mathrm{~cm}^{2} / \mathrm{m}^{2}$

$1.04(1.02-1.08)^{*}$

RVAT area index, per $1.0 \mathrm{~cm}^{2} / \mathrm{m}^{2}$

$1.00(0.94-1.05)$

DSAT area index, per $1.0 \mathrm{~cm}^{2} / \mathrm{m}^{2}$

$1.01(0.98-1.04)$

SSAT area index, per $1.0 \mathrm{~cm}^{2} / \mathrm{m}^{2}$

$1.02(0.99-1.06)$

The following parameters were simultaneously used as independent variables: age, sex, body mass index, and IVAT, RVAT, DSAT and SSAT area indexes

IVAT intraperitoneal visceral adipose tissue, RVAT retroperitoneal visceral adipose tissue, DSAT deep subcutaneous adipose tissue, SSAT superficial subcutaneous adipose tissue

$* P<0.05$
In the cross-sectional study, multiple regression analysis showed that the IVAT area index $(\beta=0.178$, $P=0.0048)$, but not the RVAT area index $(\beta=0.083$, $P=0.1815)$, was independently associated with CRP levels when the following parameters were simultaneously used as independent variables: age, sex, IVAT, RVAT, DSAT, and SSAT area indices.

To compare which abdominal fat compartment is more informative compared other compartment and to its ratios, we performed the following statistical analyses. The AUC of the IVAT area index for the prevalence of DM was larger than that of the RVAT, DSAT, or SSAT area index (Tables 4, 5 and Fig. 2). In the variables such as IVAT, and DSAT area indices, and IVAT/RVAT and

Table 4 Receiver operating characteristic curve analyses of each abdominal adipose tissue area parameter for identifying the prevalence of diabetes mellitus

\begin{tabular}{|c|c|c|c|c|c|}
\hline & AUC & $P$ & Cutoff value & Sensitivity & Specificity \\
\hline $\begin{array}{l}\text { Total adipose tissue area index }\left(\mathrm{cm}^{2} /\right. \\
\left.\mathrm{m}^{2}\right)\end{array}$ & 0.745 & $<0.0001$ & 99.4 & 0.667 & 0.728 \\
\hline VAT area index $\left(\mathrm{cm}^{2} / \mathrm{m}^{2}\right)$ & 0.804 & $<0.0001$ & 46.9 & 0.741 & 0.779 \\
\hline IVAT area index $\left(\mathrm{cm}^{2} / \mathrm{m}^{2}\right)$ & 0.809 & $<0.0001$ & 26.9 & 0.790 & 0.729 \\
\hline RVAT area index $\left(\mathrm{cm}^{2} / \mathrm{m}^{2}\right)$ & 0.751 & $<0.0001$ & 13.7 & 0.807 & 0.628 \\
\hline SAT area index $\left(\mathrm{cm}^{2} / \mathrm{m}^{2}\right)$ & 0.617 & $<0.0001$ & 37.5 & 0.828 & 0.380 \\
\hline DSAT area index $\left(\mathrm{cm}^{2} / \mathrm{m}^{2}\right)$ & 0.657 & $<0.0001$ & 25.3 & 0.351 & 0.882 \\
\hline SSAT area index $\left(\mathrm{cm}^{2} / \mathrm{m}^{2}\right)$ & 0.555 & 0.0181 & 13.1 & 0.825 & 0.286 \\
\hline VAT/SAT area ratio & 0.725 & $<0.0001$ & 0.709 & 0.754 & 0.600 \\
\hline IVAT/RVAT area ratio & 0.705 & $<0.0001$ & 1.760 & 0.684 & 0.667 \\
\hline DSAT/SSAT area ratio & 0.675 & 0.0009 & 1.579 & 0.684 & 0.644 \\
\hline
\end{tabular}

AUC area under the curve, VAT visceral adipose tissue, IVAT intraperitoneal VAT, RVAT retroperitoneal VAT, SAT subcutaneous adipose tissue, DSAT deep SAT, SSAT superficial SAT 


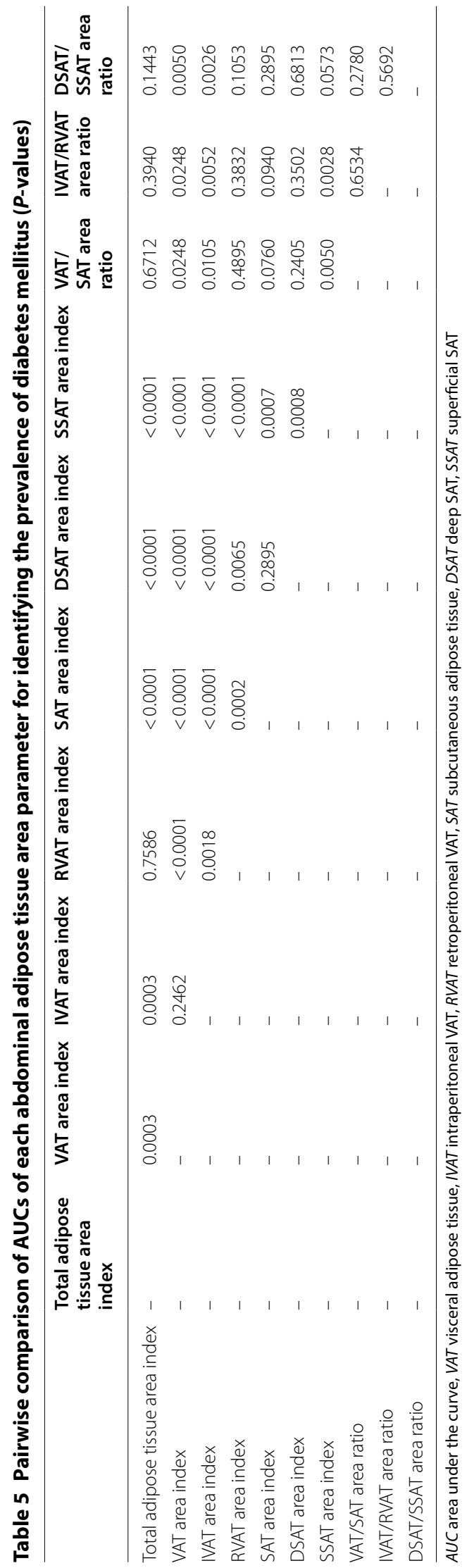




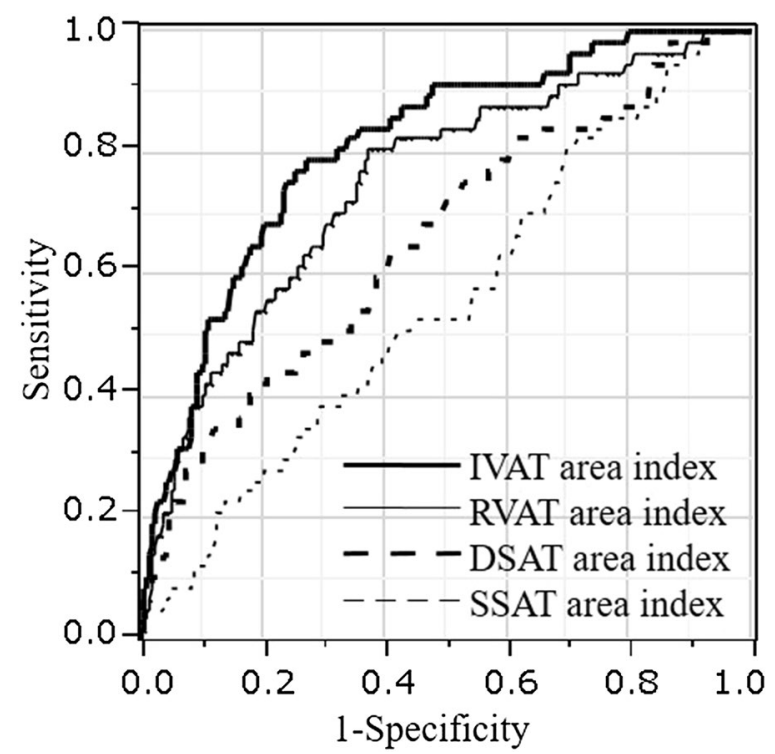

Fig. 2 Area under the receiver operating characteristic curves (AUC) of IVAT, RVAT, DSAT, and SSAT area indices for the prevalence of diabetes mellitus. VAT visceral adipose tissue, IVAT intraperitoneal VAT, RVAT retroperitoneal VAT, SAT subcutaneous adipose tissue, DSAT, deep SAT, SSAT superficial SAT, CI confidence interval

DSAT/SSAT area ratios, IVAT/RVAT area ratio was selected by Bayesian Information Criterions.

The incidence of DM across 2324 person-years was 13 per 1000 person-years (95\% CI 9-18) in 624 participants. In Cox regression analyses, the c-statistics for the following parameters was greater than 0.7: body mass index, 0.752; fasting plasma glucose, 0.885; VAT area index, 0.769; IVAT area index, 0.800, RVAT area index, 0.754; SAT area index, 0.704; DSAT area index, 0.736. In the adjusted model 1, the IVAT area index (HR, 1.02; 95\% CI $1.003-1.04$, per $1.0 \mathrm{~cm}^{2} / \mathrm{m}^{2}$ ) or the IVAT/RVAT area ratio (HR, 2.25; 95\% CI 1.40-3.43, per 1.0) was independently associated with the incidence of DM, whereas the RVAT area index was not (Table 6). In the adjusted model 2, only IVAT/RVAT area ratio (HR, 2.22; 95\% CI 1.33-3.47, per 1.0) was independently associated with the incidence of DM.

\section{Discussion}

This study has revealed two primary findings. First, the IVAT or RVAT area index, or IVAT/RVAT area ratio was independently associated with the prevalence of DM. However, the AUC of the IVAT area index for the prevalence of DM was larger than that of the RVAT area index, or IVAT/RVAT area ratio. Moreover, even after the simultaneous inclusion of the IVAT, RVAT, DSAT, and SSAT area indices in the multivariate logistic regression analysis, the IVAT area index was independently
Table 6 Adjusted hazard ratio and $95 \%$ confidence interval of each abdominal adipose tissue area parameter for incident diabetes mellitus

\begin{tabular}{lll}
\hline & Model 1 & Model 2 \\
\hline $\begin{array}{c}\text { Total adipose tissue area index, } \\
\text { per } 1.0 \mathrm{~cm}^{2} / \mathrm{m}^{2}\end{array}$ & $1.01(1.00-1.01)$ & $1.00(0.99-1.02)$ \\
VAT area index, per $1.0 \mathrm{~cm}^{2} / \mathrm{m}^{2}$ & $1.02(1.00-1.03)$ & $1.01(0.99-1.03)$ \\
IVAT area index, per $1.0 \mathrm{~cm}^{2} / \mathrm{m}^{2}$ & $1.02(1.003-1.04)^{*}$ & $1.02(0.99-1.05)$ \\
RVAT area index, per $1.0 \mathrm{~cm}^{2} / \mathrm{m}^{2}$ & $1.02(0.97-1.07)$ & $0.99(0.92-1.05)$ \\
SAT area index, per $1.0 \mathrm{~cm}^{2} / \mathrm{m}^{2}$ & $1.01(1.00-1.02)$ & $0.99(0.96-1.02)$ \\
DSAT area index, per $1.0 \mathrm{~cm}^{2} / \mathrm{m}^{2}$ & $1.01(0.99-1.03)$ & $0.98(0.95-1.02)$ \\
SSAT area index, per $1.0 \mathrm{~cm}^{2} / \mathrm{m}^{2}$ & $1.02(0.99-1.06)$ & $1.00(0.94-1.05)$ \\
VAT/SAT area ratio, per 1.0 & $2.30(0.86-5.59)$ & $2.56(0.92-6.60)$ \\
IVAT/RVAT area ratio, per 1.0 & $2.25(1.40-3.43)^{*}$ & $2.22(1.33-3.47)^{*}$ \\
DSAT/SSAT area ratio, per 1.0 & $0.96(0.52-1.55)$ & $0.89(0.48-1.47)$ \\
\hline
\end{tabular}

The following parameters were simultaneously used as independent variables: Model 1: age, sex, fasting plasma glucose at baseline examination, and each parameter for abdominal adipose tissue area, Model 2: Model 1 plus body mass index

VAT visceral adipose tissue, IVAT intraperitoneal VAT, RVAT retroperitoneal VAT, SAT subcutaneous adipose tissue, DSAT deep SAT, SSAT superficial SAT * $P<0.05$

associated with the prevalence of DM, whereas the RVAT area index was not. Second, the IVAT area index or the IVAT/RVAT area ratio was independently associated with the incidence of DM, whereas the RVAT area index was not. Moreover, in the adjustment model including body mass index, only IVAT/RVAT area ratio was independently associated with the incidence of DM, whereas the IVAT or RVAT area index was not. To the best of our knowledge, this is the first study to demonstrate the independent association of IVAT, or IVAT/RVAT area ratio, but not RVAT, with the prevalence or incidence of DM.

This is the first study to evaluate the association between DM and IVAT area based on CT evaluations. A few studies have identified an association between insulin resistance and the IVAT and RVAT areas based on findings from magnetic resonance imaging (MRI) [11, 12]. However, the results of those studies have been inconsistent. The IVAT area evaluated by MRI was a major predictor of peripheral and hepatic insulin action in 57 participants with obesity, whereas the RVAT area was not [12]. Conversely, no difference between IVAT and RVAT by MRI on insulin resistance was reported from a study among 89 obese men [11]. On the other hand, our study demonstrated the distinct associations of IVAT and RVAT with glucose metabolism, although there was a difference in the assessment tool of abdominal adipose tissue area. Indeed, unlike previous studies, our study directly compared the effects of IVAT and RVAT on glucose metabolism. Moreover, a larger number of participants were evaluated than in previous studies. Our study 
also demonstrated that the IVAT/RVAT area ratio was important for the incidence of DM, even after adjusted by body mass index.

The insulin action was negatively associated with the VAT area, because increased delivery of free fatty acids (FFAs) in insulin sensitive tissues significantly impairs insulin action [11, 24, 25]. In particular, the adverse effects associated with VAT may be related to the portally drained FFAs originating from IVAT [25, 26]. Mice that received a fat transplant which drained into the portal vein had higher blood glucose levels after a glucose load than mice that received a fat transplant that drained into the inferior vena cava or the sham-operated mice [27]. The portal theory is a possible hypothesis of the association between glucose metabolism and the IVAT $[25,27]$. The link between the VAT and insulin resistance involves the close association with fatty liver diseases. The IVAT relates to portal circulation, whereas the RVAT relates to the systemic circulation. The fatty tissue, which was drained into the portal vein, was associated with hepatic insulin resistance because the liver is directly exposed to FFAs and cytokines released from the fatty tissue [27-29]. Moreover, the secretion of interleukin (IL)-6 from adipose tissue causes hepatic insulin resistance [30]. The plasma IL-6 levels were 50\% higher in the portal vein than in the systemic circulation, and portal vein IL-6 levels were associated with the systemic CRP levels [31]. Indeed, the results from this study showed that the IVAT area index was related to the CRP levels, whereas the RVAT area index was not. Besides, a study demonstrated that hs-CRP levels were associated with visceral fat amount and dysfunction in obese females [32]. On the other hand, adiponectin, leptin, and resistin are associated with insulin resistance [33]. Previous study demonstrated that adiponectin level was inversely related to IVAT, but not associated with SAT, and RVAT, and leptin was associated with all part of adipose tissue [33]. However, there was no association between resistin and adipose tissue distribution [33].

This study has some limitations. First, although a larger number of participants were evaluated than in previous studies that used MRI $[11,12]$, the relatively small number of the prevalence or incidence of DM limited the number of independent variables that could be included in the multivariate analysis. Therefore, we performed statistical analyses on many models. Second, the study participants were only Japanese men and women, and it is uncertain whether the results can be generalized in other ethnicities. Besides, abdominal CT scanning was performed on request of individuals. This may have introduced an inherent bias in our study design. Finally, CT is a reliable method to evaluate the IVAT or RVAT area [9], but the automated analysis of the IVAT or RVAT area is difficult; therefore, these two parameters were evaluated semi-automatically. Previous studies that used CT, similarly as in this study, indicated that the IVAT or RVAT areas had a high correlation between the first and second manual measurements [9].

In conclusion, the IVAT, but not the RVAT, as evaluated by $\mathrm{CT}$, was associated with the prevalence or incidence of DM. Indeed, IVAT and RVAT might have distinct functions in terms of the prevalence or incidence of DM. Evaluating IVAT and RVAT may enable early detection of prediabetes in obese patients. Further research is required to provide evidence of the effectiveness and feasibility of evaluating IVAT and RVAT.

\section{Abbreviations}

VAT: Visceral adipose tissue; IVAT: Intraperitoneal VAT; RVAT: Retroperitoneal VAT; SAT: Subcutaneous adipose tissue; DSAT: Deep SAT; SSAT: Superficial SAT; Cl: Confidence interval; DM: Diabetes mellitus; CT: Computed tomography; CRP: C-reactive protein; FPG: Fasting plasma glucose; LDL-C: Low-density lipoprotein cholesterol; HDL-C: High-density lipoprotein cholesterol; HU: Hounsfield unit; OR: Odds ratio; HR: Hazards ratio; ROC: Receiver operator characteristic; AUC: Area under the ROC curves; FFA: Free fatty acid.

\section{Acknowledgements}

We acknowledge all the staff members of the medical health checkup center at the Nishimura Clinic.

\section{Authors' contributions}

MT designed and performed statistical analysis and wrote the manuscript. MF reviewed and edited the manuscript. $\mathrm{HN}$ reviewed and edited the manuscript. $\mathrm{HO}$ and $\mathrm{YH}$ contributed to the discussion. MK researched the data. All authors read and approved the final manuscript.

\section{Funding}

This research did not receive any specific grant from funding agencies in the public, commercial, or not-for-profit sectors.

\section{Availability of data and materials}

Data from this study can be acquired from the corresponding author upon reasonable request.

\section{Ethics approval and consent to participate}

All participants were informed about the study and informed consent was obtained from all the participants. The study adhered to the Declaration of Helsinki and ethics approval was obtained from the Institutional Review Board of Kyoto Prefectural University of Medicine.

\section{Consent for publication}

Not applicable.

\section{Competing interests}

Y.H. has received grants from Asahi Kasei Pharma and honoraria from Mitsubishi Tanabe Pharma Corp, and Novo Nordisk Pharma Ltd outside of the submitted work. M.F. has received grants from Takeda Pharma Co. Ltd., Sanofi K.K., Kissei Pharma Co. Ltd., Mitsubishi Tanabe Pharma Corp, Astellas Pharma Inc., Nippon Boehringer Ingelheim Co. Ltd., Daiichi Sankyo Co. Ltd., MSD K.K., Sanwa Kagagu Kenkyusho Co., Ltd., Kowa Pharma Co. Ltd., Kyowa Kirin Co., Ltd., Sumitomo Dainippon Pharma Co., Ltd., Novo Nordisk Pharma Ltd., Ono Pharma Co. Ltd., Eli Lilly Japan K.K., Taisho Pharma Co., Ltd., Tejin Pharma Ltd., Nippon Chemiphar Co., Ltd., Johnson \& Johnson K.K. Medical Co., Abbott Japan Co. Ltd., and Terumo Corp.; and received honoraria from Teijin Pharma Ltd., Arkray Inc., Kissei Pharma Co., Ltd., Novo Nordisk Pharma Ltd., Mitsubishi Tanabe Pharma Corp., Sanofi K.K., Takeda Pharma Co. Ltd., Astellas Pharma Inc., 
MSD K.K., Kyowa Kirin Co. Ltd., Sumitomo Dainippon Pharma Co. Ltd., Daiichi Sankyo Co. Ltd., Ono Pharma Co. Ltd., Sanwa Kagaku Kenkyusho Co. Ltd., Nippon Boehringer Ingelheim Co., Ltd., Taisho Pharma Co., Ltd., Bayer Yakuhin, Ltd., AstraZeneca K.K., Mochida Pharma Co. Ltd., Abbott japan Co. Ltd., Eli Lilly Japan K.K., Medtronic Japan Co. Ltd., and Nipro Corp. outside the submitted work. The sponsors were not involved in the study design or the collection, analysis, and interpretation of the data. Moreover, the sponsors were not involved in the writing or decision to submit the article for publication in the manuscript. The authors, their immediate families, and any affiliated research foundations have not received any financial payments or other benefits from any commercial entity related to the participants of this article. The authors are affiliated with a department financially supported by pharmaceutical companies and declare that they have not received any funding for this study, and this affiliation does not alter their adherence to the journal policies on sharing data and materials. The other authors have no disclosures.

\section{Author details}

1 Department of Endocrinology and Metabolism, Kyoto Prefectural University of Medicine, Graduate School of Medical Science, 465 Kajii-cho, Kawaramachi-Hirokoji, Kamigyo-ku, Kyoto 602-8566, Japan. ${ }^{2}$ Department of Internal Medicine, Matsushita Memorial Hospital, Osaka, Japan. ${ }^{3}$ Medical Corporation Soukenkai, Nishimura Clinic, Kyoto, Japan.

Received: 20 August 2020 Accepted: 17 November 2020

\section{Published online: 25 November 2020}

\section{References}

1. Selvin E, Steffes MW, Zhu H, Matsushita K, Wagenknecht L, Pankow J, et al. Glycated hemoglobin, diabetes, and cardiovascular risk in nondiabetic adults. N Engl J Med. 2010;362:800-11. https://doi.org/10.1056/NEJMo a0908359.

2. Fox CS, Coady S, Sorlie PD, Levy D, Meigs JB, D'Agostino RB Sr, et al. Trends in cardiovascular complications of diabetes. JAMA. 2004;292:2495-9. https://doi.org/10.1001/jama.292.20.2495.

3. Miyazaki Y, Glass L, Triplitt C, Wajcberg E, Mandarino LJ, DeFronzo RA. Abdominal fat distribution and peripheral and hepatic insulin resistance in type 2 diabetes mellitus. Am J Physiol Endocrinol Metab. 2002;283:E1135-43. https://doi.org/10.1152/ajpendo.0327.2001.

4. Rodríguez A, Becerril S, Hernández-Pardos AW, Frühbeck G. Adipose tissue depot differences in adipokines and effects on skeletal and cardiac muscle. Curr Opin Pharmacol. 2020;52:1-8. https://doi.org/10.1016/j. coph.2020.04.003

5. Vecchié A, Dallegri F, Carbone F, Bonaventura A, Liberale L, Portincasa $P$, et al. Obesity phenotypes and their paradoxical association with cardiovascular diseases. Eur J Intern Med. 2018;48:6-17. https://doi. org/10.1016/j.ejim.2017.10.020.

6. Guglielmi V, Sbraccia P. Epicardial adipose tissue: at the heart of the obesity complications. Acta Diabetol. 2017;54:805-12. https://doi. org/10.1007/s00592-017-1020-z.

7. Fujioka S, Matsuzawa Y, Tokunaga K, Tarui S. Contribution of intraabdominal fat accumulation to the impairment of glucose and lipid metabolism in human obesity. Metabolism. 1987;36:54-9. https://doi. org/10.1016/0026-0495(87)90063-1.

8. Matsha TE, Ismail S, Speelman A, Hon GM, Davids S, Erasmus RT, et al. Visceral and subcutaneous adipose tissue association with metabolic syndrome and its components in a South African population. Clin Nutr ESPEN. 2019;32:76-81. https://doi.org/10.1016/j.clnesp.2019.04.010.

9. Kullberg J, Hedström A, Brandberg J, Strand R, Johansson L, Bergström $\mathrm{G}$, Ahlström H. Automated analysis of liver fat, muscle and adipose tissue distribution from CT suitable for large-scale studies. Sci Rep. 2017;7:10425. https://doi.org/10.1038/s41598-017-08925-8.

10. Mantatzis M, Milousis T, Katergari S, Delistamatis A, Papachristou DN, Prassopoulos P. Abdominal adipose tissue distribution on MRI and diabetes. Acad Radiol. 2014;21:667-74. https://doi.org/10.1016/j.acra.2014.01.009.

11. Ross R, Aru J, Freeman J, Hudson R, Janssen I. Abdominal adiposity and insulin resistance in obese men. Am J Physiol Endocrinol Metab. 2002;282:E657-63. https://doi.org/10.1152/ajpendo.00469.2001.
12. Koska J, Stefan N, Votruba SB, Smith SR, Krakoff J, Bunt JC. Distribution of subcutaneous fat predicts insulin action in obesity in sex-specific manner. Obesity. 2008;16:2003-9. https://doi.org/10.1038/oby.2008.292.

13. Kelley DE, Thaete FL, Troost F, Huwe T, Goodpaster BH. Subdivisions of subcutaneous abdominal adipose tissue and insulin resistance. Am J Physiol Endocrinol Metab. 2000;278:E941-8. https://doi.org/10.1152/ ajpendo.2000.278.5.E941.

14. Sniderman AD, Bhopal R, Prabhakaran D, Sarrafzadegan N, Tchernof A. Why might South Asians be so susceptible to central obesity and its atherogenic consequences? The adipose tissue overflow hypothesis. Int J Epidemiol. 2007;36:220-5. https://doi.org/10.1093/ije/dyl245.

15. Marinou K, Hodson L, Vasan SK, Fielding BA, Banerjee R, Brismar K, et al. Structural and functional properties of deep abdominal subcutaneous adipose tissue explain its association with insulin resistance and cardiovascular risk in men. Diabetes Care. 2014;37:821-9. https://doi. org/10.2337/dc13-1353.

16. Shuster A, Patlas M, Pinthus JH, Mourtzakis M. The clinical importance of visceral adiposity: a critical review of methods for visceral adipose tissue analysis. Br J Radiol. 2012;85:1-10. https://doi.org/10.1259/bjr/38447238.

17. Alberti KG, Zimmet P, Shaw J. Metabolic syndrome-a new world-wide definition. A consensus statement from the International Diabetes Federation. Diabet Med. 2006;23:469-80. https://doi.org/10.111 1/j.1464-5491.2006.01858.x.

18. Tanaka M, Okada H, Hashimoto Y, Kumagai M, Nishimura H, Oda Y, et al. Relationship between metabolic syndrome and trunk muscle quality as well as quantity evaluated by computed tomography. Clin Nutr. 2020a;39:1818-25. https://doi.org/10.1016/j.numecd.2020.02.021.

19. Tanaka M, Okada H, Hashimoto Y, Kumagai M, Nishimura H, Fukui M. Trunk muscle quality and quantity predict the development of metabolic syndrome and the increase in the number of its components in individuals without metabolic syndrome. Nutr Metab Cardiovas Dis. 2020a;30:1161-8. https://doi.org/10.1016/j.numecd.2020.02.021.

20. Tanaka M, Okada H, Hashimoto Y, Kumagai M, Nishimura H, Fukui M. Low-attenuation muscle is a predictor of diabetes mellitus: a populationbased cohort study. Nutrition. 2020b;74:110752. https://doi.org/10.1016/j. nut.2020.110752.

21. Tanaka M, Okada H, Hashimoto $Y$, Kumagai M, Nishimura H, Oda Y, et al. Relationship between nonalcoholic fatty liver disease and muscle quality as well as quantity evaluated by computed tomography. Liver Int. 2020b;40:120-30. https://doi.org/10.1111/liv.14253.

22. American Diabetes Association. (2) Classification and diagnosis of diabetes. Diabetes Care. 2015;2015(38):S8-16. https://doi.org/10.2337/ dc15-S005

23. Kvist $H$, Sjöström $L$, Tylén $U$. Adipose tissue volume determinations in women by computed tomography: technical considerations. Int J Obes. 1986;10:53-67.

24. Ferrannini E, Barrett EJ, Bevilacqua S, DeFronzo RA. Effect of fatty acids on glucose production and utilization in man. J Clin Investig. 1983;72(5):1737-47. https://doi.org/10.1172/JCl111133.

25. Björntorp P. "Portal" adipose tissue as a generator of risk factors for cardiovascular disease and diabetes. Arteriosclerosis. 1990;10:493-6. https://doi. org/10.1161/01.ATV.10.4.493.

26. Björntorp P. Metabolic implications of body fat distribution. Diabetes Care. 1991;14:1132-43. https://doi.org/10.2337/diacare.14.12.1132.

27. Rytka JM, Wueest S, Schoenle EJ, Konrad D. The portal theory supported by venous drainage-selective fat transplantation. Diabetes. 2011;60:5663. https://doi.org/10.2337/db10-0697.

28. Jensen MD. Role of body fat distribution and the metabolic complications of obesity. J Clin Endocrinol Metab. 2008;93:S57-63. https://doi. org/10.1210/jc.2008-1585.

29. Kabir M, Catalano KJ, Ananthnarayan S, Kim SP, Van Citters GW, Dea MK, et al. Molecular evidence supporting the portal theory: a causative link between visceral adiposity and hepatic insulin resistance. Am J Physiol Endocrinol Metab. 2005;288:E454-61. https://doi.org/10.1152/ajpen do.00203.2004.

30. Carey AL, Febbraio MA. Interleukin-6 and insulin sensitivity: friend or foe? Diabetologia. 2004;47:1135-42. https://doi.org/10.1007/s0012 5-004-1447-y. 
31. Fontana L, Eagon JC, Trujillo ME, Scherer PE, Klein S. Visceral fat adipokine secretion is associated with systemic inflammation in obese humans. Diabetes. 2007;56:1010-3. https://doi.org/10.2337/db06-1656.

32. Carbone F, Nulli Migliola E, Bonaventura A, Vecchié A, De Vuono S, Ricci $M A$, et al. High serum levels of $C$-reactive protein (CRP) predict beneficial decrease of visceral fat in obese females after sleeve gastrectomy. Nutr Metab Cardiovasc Dis. 2018;28:494-500. https://doi.org/10.1016/j.numec d.2018.01.014.

33. Hsieh CJ, Wang PW, Chen TY. The relationship between regional abdominal fat distribution and both insulin resistance and subclinical chronic inflammation in non-diabetic adults. Diabetol Metab Syndr. 2014;6:49. https://doi.org/10.1186/1758-5996-6-49.

\section{Publisher's Note}

Springer Nature remains neutral with regard to jurisdictional claims in published maps and institutional affiliations.
Ready to submit your research? Choose BMC and benefit from:

- fast, convenient online submission

- thorough peer review by experienced researchers in your field

- rapid publication on acceptance

- support for research data, including large and complex data types

- gold Open Access which fosters wider collaboration and increased citations

- maximum visibility for your research: over $100 \mathrm{M}$ website views per year

At BMC, research is always in progress.

Learn more biomedcentral.com/submissions 